El autor del presente texto propone, desde el título, pensar en la gente que habitó y creó en Chancay un paisaje que actualmente se está perdiendo, principalmente porque los habitantes modernos no podemos integrarlo al proceso de construcción de nuestras identidades culturales, al entendimiento de lo que llamamos peruanidad.

Sin duda se trata de un texto patrimonialista, que introduce al lector al conocimiento del mundo chancay, generando a lo largo del proceso compromisos afectivos por su defensa y conservación mediante una estructura textual -expresiones culturales, cronología, contextos funerarios, asentamientos y arquitectura- que pone en valor dicha cultura, y una abundante y multidisciplinaria información bibliográfica.

El manejo descriptivo y teórico de la información arquitectónica resulta muy interesante, especialmente para el neófito ajeno al mundo ancestral chancay y al sentimiento patrimonial necesario para comprender la importancia del testimonio arqueológico arquitectónico como indicador cultural en el estudio de las poblaciones de las sociedades antiguas.

En concordancia con su preocupación patrimonial, el autor describe la realidad actual de los testimonios arqueológicos de los asentamientos chancay: "Algo que inquieta sobre manera, es que dentro de todo el valle, ningún sitio arqueológico posee la protección física por parte del Estado o del Instituto Nacional de Cultura, y ello origina su destrucción paulatina... pero también las áreas de cultivo tienden a expandirse, buscando mejorar su productividad y aquí la destrucción es inminente: cada vez avanzan más metros sobre aquellos límites invisibles de los sitios arqueológicos... resulta paradójica tanta destrucción, pues aquello que se destruye merma el potencial turístico y cultural que podría propiciar el desarrollo socioeconómico en busca de consolidar la identidad de la zona" (Guzmán, 2016, p. 29).

En cuanto a la estructura del libro, destaca la presentación en el prólogo a dos connotados patrimonialistas: la doctora Ruth Shady Solís y el arquitecto José Canziani Amico, cuyas opiniones resaltan su importancia científica y especializada. Esta publicación consta de ocho capítulos sintetizados en el resumen e introducción, que dan cuenta del proceso de construcción académica para organizar las ideas y el orde-

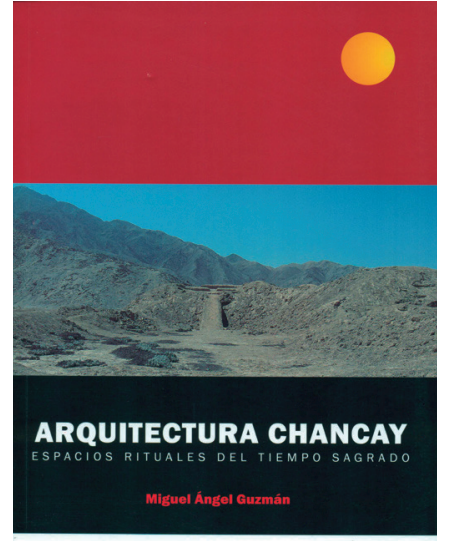

\section{ARQUITECTURA CHANCAY ESPACIOS RITUALES DEL TIEMPO SAGRADO}

MIGUEL GUZMÁ́N

UNIVERSIDAD RICARDO PALMA, LIMA-PERÚ, 2016.

RESEÑA DE INÉS DEL ÁGUILA RÍOS

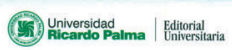

namiento metodológico correspondiente. La bibliografía general y específica, así como los anexos, demuestran su interés por aportar datos específicos, valiosa base para emprender futuras pesquisas. Entre los anexos destacan, para la investigación arqueológica y las ciencias sociales, el glosario arquitectónico y los cuadros técnicos.

En los primeros cinco capítulos se aportan novedades de carácter teórico y metodológico para el estudio del testimonio arquitectónico como indicador cultural, aportes que se complementan con un conjunto sistemático actualizado de gráficos y fotografías de importancia para la construcción del devenir de este testimonio arquitectónico prehispánico en la costa norcentral.

El primer capítulo, "Antecedentes", es especialmente importante, porque reúne una exhaustiva compilación de sitios investigados en la zona, lo cual permite plantear la idea que titula el libro. En él se desarrollan acertadamente indicadores clave para comprender la cultura chancay: sus expresiones culturales, cronología, contextos funerarios, asentamientos y arquitectura.

En los cuatro capítulos siguientes, desarrolla respectivamente cada uno de los cuatro aspectos ya señalados, realizando un sólido balance de la literatura científica, e investigadores especializados y sus principales aportes teórico-metodológicos, especialmente aquellos derivados del estudio de Pisquillo Chico. La narrativa se caracteriza por su enfoque interdisciplinar: etnohistoria, lingüística, geografía $y$, en general, de las ciencias sociales. Pisquillo Chico fue elegido como sitio emblemático y laboratorio de exploración del tema, mediante el despliegue de datos y reflexiones en cuanto al tratamiento del dato arqueológico arquitectónico.

En los capítulos 6, 7 y 8, titulados respectivamente "Resultados e Interpretación", "Discusión" y "Conclusiones", el autor consolida ideas planteadas en los capítulos anteriores, y propone reflexiones críticas respecto de las teorías en arqueología y arquitectura que denotan la importante bibliografía consultada y contrastada con registros de campo. Entre las conclusiones, resulta de interés interdisciplinar el uso de edificios con rampa en lugar de pirámide con rampa para caracterizar los edificios chancay y la arquitectura costeña del Intermedio Tardío, la utilización de categorías conceptuales que los arqueólogos adjudican a determinadas formas arquitectónicas principalmente fundamentándose en crónicas, y el uso continuo de la categoría ciudad sin contar con el peso académico referido al proceso cultural andino-amazónico. En cuanto a lo último, el autor recomienda que la construcción conceptual de ciudad como estructura urbana social y funcional debe incorporar tres nociones básicas: ser lugar de residencia (vivienda), contar con un sistema de uso de suelos diferenciado y estar articulada internamente por medio de circuitos espaciales (vías de comunicación o recorridos establecidos).

Finalmente, el autor reitera que para entender a la sociedad prehispánica chancay, así como a las demás sociedades del Intermedio Tardío, es importante profundizar en los conceptos de yanantin y tinkuy, y en el significado de los principios andinos de dualidad y tripartición. El acercamiento a los conceptos citados, explica el autor, aportan criterios para entender la simbología de las formas, y el diseño arquitectónico y el mensaje de este valioso libro. 